\title{
EVALUATION OF ANALYTICAL METHODS TO ADDRESS TUNGSTEN SPECIATION
}

\author{
A. OGUNDIPE ${ }^{1}$ \\ J. PAVLOV ${ }^{1}$ \\ W. BRAIDA ${ }^{1^{*}}$ \\ A. KOUTSOSPYROS ${ }^{2}$ \\ G. SEN ${ }^{1}$ \\ C. CHRISTODOULATOS ${ }^{1}$ \\ G. O'CONNOR ${ }^{3}$
}

Received: $31 / 10 / 08$

Accepted: 24/2/09

\author{
${ }^{1}$ Center for Environmental Systems, \\ Stevens Institute of Technology, Hoboken, NJ 07030, USA \\ ${ }^{2}$ University of New Haven, \\ West Haven, CT 06516, USA \\ ${ }^{3}$ US Army, Demilitarization and Environmental Technology Division \\ Picatinny, NJ 07806, USA
}

\section{ABSTRACT}

Tungsten in solution may exist as a wide variety of species depending on concentration, $\mathrm{pH}$, and aging time. Despite a substantial number of studies on this topic, the speciation of tungsten in aqueous solutions is still not completely understood. To address issues of fate, transport and potential bioavailability, it is necessary to be able to assess the speciation of tungsten in environmental systems. This study investigates the use of Laser Desorption/lonization mass spectrometry combined with a Time-of-Flight mass analyzer (LDITOF) as well as Raman spectroscopy as potential techniques in speciation studies. Raman spectroscopy has been successful in identifying the dominant species under a narrow range of conditions. The ultimate goal is to extend the range of conditions and concentrations while also identifying subordinate species.

KEYWORDS: Tungsten speciation, Environmental, LDI-TOF, Raman.

\section{INTRODUCTION}

Tungsten (chemical symbol W) has been used extensively in various applications including lighting applications, welding electrodes, tool steels, hard metal (tungsten carbide), superalloys, x-ray tubes, glass-to-metal seals, solar energy devices, electrical contacts, electron emitters, golf club components, darts, and fishing weights. It has recently been touted as a replacement for lead in ammunitions for civil and military uses. The increasing use of tungsten has resulted in its widespread release into the environment. Previous research has shown that once released into the environment, tungsten heavy alloys (WHA) and composites release substantial amounts of $\mathrm{W}$ into the soil solution resulting in changes in the soil chemistry and microbiology $(\mathrm{pH}$, dissolved oxygen, soil respiration, plant and earthworm toxicity) (Dermatas et al., 2004). In 2002, tungsten was recommended for toxicological and carcinogenesis studies by the National Center for Environmental Health of Centers for Disease Control and Prevention (ATSDR, 2003). Furthermore, in April 2008, the United States Environmental Protection Agency (USEPA) added tungsten to the list of emerging contaminants. However, very little information exists on tungsten toxicological effects, though preliminary studies indicate that these effects may be related to speciation. Tungsten exists as a wide variety of species in solution depending on concentration, $\mathrm{pH}$, and aging time. Monotungstate, $\mathrm{WO}_{4}{ }^{2-}$, undergoes several polycondensation reactions forming polyoxotungstates. Tajima investigated the effect of polyoxotungstates on biological and biochemical systems. He reported that polyanionic species could be responsible for the observed biological effects including the inhibition of several anion-sensitive enzymes that could result in gene damage in microorganisms (Tajima, 2003). Recent studies by Strigul et 
al. (2008) indicate a significant difference in acute toxic responses by fish when exposed to polyoxotungstates compared to exposure to monomeric tungstate under similar conditions. The acute toxicity of metatungstate to Poecilia reticulate appears to be 4-6 fold larger than the tungstate toxicity (expressed in tungsten $\mathrm{mg} \mathrm{l}^{-1}$ ).

Despite a substantial number of studies on this topic, spanning several decades and featuring a wide variety of techniques, the speciation of tungsten in aqueous solutions is still not completely understood. This is largely due to the extremely slow kinetics of some of the condensation reactions and the poorly understood impact of concentration and time on speciation. It is agreed upon that at alkaline $\mathrm{pH}>10$, monomeric $\mathrm{WO}_{4}{ }^{2-}$ is the only species in solution. It has also been reported that at concentration values $<5 \times 10^{-5} \mathrm{M}$, no polyanions are formed ( $\mathrm{Ng}$ and Gulari, 1984). However, differences in characterization techniques employed have often resulted in different conclusions adding to the confusion on the nature of the polyanionic species. For example, paratungstate $A$, the predominant species present in unaged samples between $\mathrm{pH} 5$ and 7 , was originally believed to have the formula $\mathrm{HW}_{6} \mathrm{O}_{21}{ }^{5-}$ (Jander et al., 1929). This position was upheld by many subsequent reports. Sasaki (1961) considered $\mathrm{W}_{7} \mathrm{O}_{24}{ }^{6-}$ as a possible formula but ruled it out due to "better fit" to the experimental data of the $\mathrm{HW}_{6} \mathrm{O}_{21}{ }^{5-}$ formula. Currently, $\mathrm{W}_{7} \mathrm{O}_{24}{ }^{6-}$ is widely accepted as the correct formula for paratungstate A. Cruywagen and Van der Merwe (1987) have proposed, however, that the species $\left[\mathrm{W}_{6} \mathrm{O}_{20}(\mathrm{OH})_{2}\right]^{6-}$ exists, but is actually a minor unstable species that could attain only a maximum of $11 \%$ total tungsten in solution. Various techniques, including electrometric and conductometric titrations, spectrophotometric measurements, Glauber-salt cryoscopy isomatrix electromigration, proton magnetic resonance (PMR), and potentiometric and calorimetric titrations, have been used for the characterization of tungsten-water interaction products. Nuclear magnetic resonance (NMR), electrospray ionization mass spectrometry (ESI-MS) and Raman spectroscopy have also been used in recent studies. A Raman study by Shijun et al. (1998) presented a detailed analysis of the predominant species in solution at varying $\mathrm{pH}$ using very high concentrations of sodium tungstate. They successfully assigned Raman lines for the $\mathrm{WO}_{4}{ }^{2-}$, paratungstate $\mathrm{A}$ and paratungstate $\mathrm{B}$ species and suggested possible lines for the metatungstate species. In addition to the established predominant species, most new studies have also acknowledged the possibility of the existence of various low concentration species and metastable species, some of which might have been previously detected but discarded as non-probable. Although $\mathrm{WO}_{4}{ }^{2-}$ is agreed upon as the only species present at $\mathrm{pH}>10$, some studies have proposed the existence of a dimeric species $\mathrm{W}_{2} \mathrm{O}_{7}{ }^{2-}$ in the $\mathrm{pH}$ range from 10 to 7 or even at lower $\mathrm{pH}$. Chojnacka (1971) reports that this species could represent as much as $4.5 \%$ to $13.3 \%$ of the total amount of $\mathrm{W}$ in $0.01 \mathrm{M}$ and $0.02 \mathrm{M}$ samples, respectively and up to $20 \%$ in $0.05 \mathrm{M}$ samples. $\mathrm{Ng}$ and Gulari (1984) suggested the existence of a $\left[\mathrm{W}_{24} \mathrm{O}_{72}(\mathrm{OH})_{12}\right]^{12-}$ species in aged samples. Hastings and Howarth (1992) identified six metatungstate species and five metastable anions which are believed to slowly convert to metatungstate $\left(\alpha-\left[\mathrm{H}_{2} \mathrm{~W}_{12} \mathrm{O}_{40}\right]^{6-}\right.$. They also proposed the existence of $W_{11}$ species and provided a detailed scheme which Cruywagen (2000) adapted. Thermodynamic values of formation presented thus far (Cruywagen et al., 2000; Smith et al., 1987) are generally limited to certain species and are obtained under narrow ranges of conditions that limit severely their applicability. This accounts for the absence of tungsten equilibrium data in current equilibrium modeling software.

To address issues of fate, transport and potential bioavailability, it is necessary to be able to qualitatively and quantitatively assess the speciation of tungsten in environmental systems. In a recent study, Bednar et al. (2007) investigated the possibility of using an HPLC-ICP-MS technique for detection and characterization of tungsten species in aqueous samples. Their method was successful in quantitative detection of monomeric species. However, while the detection of polyoxotungstates as a group was achieved, the quantitative measurement of total polymeric species was only partially successful. The authors also showed that aqueous samples extracted from contaminated soils could contain polymeric species as much as fifty percent of the total tungsten concentration. The method was however unable to resolve and identify the different polymeric species present making it inapplicable for full qualitative/quantitative analysis. 
Previous studies (Ogundipe, 2006) have shown the limitations of Fourier-transform infrared spectroscopy (FTIR) and ion chromatography-mass spectrometry (IC-MS), which relate to the weak signals of tungstate species in the IR region and the decomposition and formation of polytungstates in the MS cone. FTIR analyses of tungsten salt solutions suggest changes in molecular and bond structures of tungsten species in samples aged for 6 months. This current effort employs the use of Raman spectroscopy as well as Laser Desorption/lonization mass spectrometry combined with a time-of-flight mass analyzer (LDI-TOF). Raman spectroscopy has been successful in identifying the dominant species under a narrow range of conditions. LDI-TOF makes use of the absorption of laser light by a solid sample layer. Preliminary studies using these two methods show promising results in the analyses of tungsten species.

\section{MATERIALS AND METHODS}

\subsection{LDI-TOF}

The general setup of LDI ion sources is comparatively simple (Figure 1). The pulse of laser light is focused onto a small spot (typically $0.05-0.2 \mathrm{~mm}$ in diameter). Variable beam attenuation in the laser optical path is employed to control the irradiance. LDI ion sources are generally operated at ambient temperature. The energy uptake upon laser irradiation causes evaporation and ionization of the sample. When combined with a time-of-flight (TOF) mass analyzer, the latter technique is capable of producing mass spectra of very large molecules, especially synthetic and biopolymers (proteins and nucleic acids), of up to about 100,000 u molecular mass. This has made LDI indispensable to biochemistry, but the technique has only recently started being applied to small molecules and inorganic materials. LDI-TOF mass spectrometry, given the right conditions, is a very sensitive analytical technique, requiring a sample load of about 1 microgram. The ionization method is very "soft", that is, a molecular ion is generally present and little fragmentation (daughter-ion formation) occurs, even with very large molecules. In addition, very little sample preparation is necessary: all that is needed is a few microliters of solution deposited on a stainless steel plate and allowed to dry. In an effort to shed light on the tungsten speciation in aqueous solutions, LDI analysis was performed on a Micromass TofSpec-2E mass spectrometer using $100 \mathrm{mg} \mathrm{I}^{-1}(\mathrm{~W})$ freshly made solutions of three tungsten salts - sodium tungstate $\left(\mathrm{Na}_{2} \mathrm{WO}_{4} \cdot 2 \mathrm{H}_{2} \mathrm{O}\right)$, sodium metatungstate $\left(3 \mathrm{Na}_{2} \mathrm{WO}_{4} \cdot 9 \mathrm{WO}_{3} \cdot \mathrm{xH}_{2} \mathrm{O}\right)$ and ammonium paratungstate $\left(\left(\mathrm{NH}_{4}\right)_{10} \mathrm{H}_{2}\left(\mathrm{~W}_{2} \mathrm{O}_{7}\right)_{6} \cdot \mathrm{xH}_{2} \mathrm{O}\right)$. The $\mathrm{pH}$ of the solutions was not adjusted. In each case, a $1 \mu \mathrm{L}$ drop of analyte solution was allowed to dry on the LDI plate, yielding $1 \mu \mathrm{g}$ solid sample to be exposed to the laser.

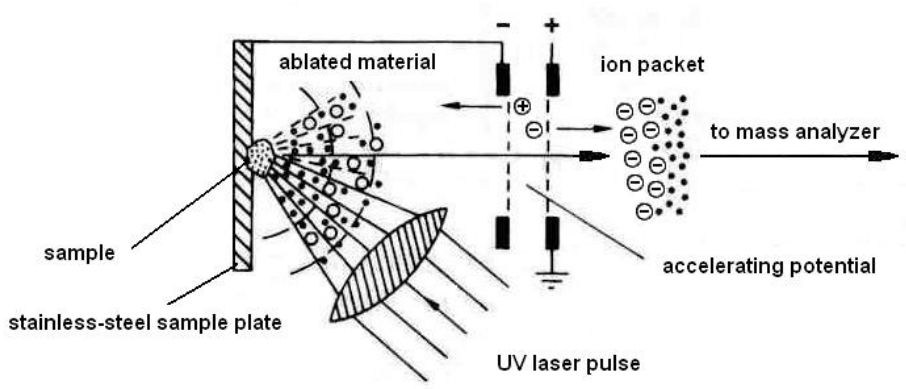

Figure 1. Schematic of a laser desorption ion source

\subsection{Raman Spectroscopy}

The Raman spectroscopic analyses of three pure salts of tungsten - sodium tungstate, sodium metatungstate, and ammonium paratungstate - were performed to obtain pure spectra of the three major tungsten species. The spectra were obtained using a Nicolet Almega XR Dispersive Raman spectrometer by Thermo Scientific. The samples were held for analysis in $10 \mathrm{~mm}$ NMR tubes. Based on previous test runs, it was determined that the active region for the tungsten species is between $1050 \mathrm{~cm}^{-1}$ and $150 \mathrm{~cm}^{-1}$ consequently the analyses were limited to this region. 


\section{RESULTS AND DISCUSSION 3.1 LDI-TOF}

Negative-ion LDI produced only singly charged ions, as evidenced by the 1 mass unit spacing between neighboring tungsten isotopic peaks. All clusters of peaks corresponded to tungsten species and displayed the characteristic tungsten isotopic patterns. The three tungstates subjected to LDI display distinctly different mass spectra. The spectra of sodium metatungstate and ammonium paratungstate are much richer, reflecting the tendency of tungsten to form polymeric ions.

The spectra are presented in various zoom scales highlighting the peaks that are characteristic to each sample. This is the key to potentially using the method for qualitative and semi-quantitative analyses of environmental samples. The spectra obtained from the three different samples are compared in Figure 2. The stacked view indicates that sodium tungstate (representing the monomeric form of tungsten) features some unique peaks below $\mathrm{m} / \mathrm{z} 600$ which are not present in the polymeric samples. A strong peak cluster centered at $\mathrm{m} / \mathrm{z} 249$ corresponds to $\mathrm{HWO}_{4}^{-}$(Figure 3). The sodium tungstate spectrum also features a cluster centered at $\mathrm{m} / \mathrm{z} 798$ and absent from the polymeric samples.

In addition, sodium tungstate displays no significant peaks above $\mathrm{m} / \mathrm{z} 900$. Hence the presence of peaks above $\mathrm{m} / \mathrm{z} 900$ is indicative of polymeric tungsten species. Comparing the two polymeric samples, ammonium paratungstate and sodium metatungstate, some similarities are observed. Generally, there are shifts in comparable peak clusters featured by both samples. These shifts could be due to the differences in the structure and arrangement of each species. Sodium metatungstate has a cluster $\mathrm{m} / \mathrm{z} 735$ which is also present in sodium tungstate but absent in the paratungstate sample. In addition, ammonium paratungstate has a cluster centered at $\mathrm{m} / \mathrm{z} 3088$ (Figure 5) which was not observed in sodium metatungstate (Figure 4). However, considering that comparable peaks generally had higher intensities in the paratungstate spectra, it could be that the 3088 peak was too weak in the sodium metatungstate spectra. These higher intensities correspond to a higher abundance which suggests that paratungstate is ultimately a more stable form. More detailed analysis needs to be performed to qualitatively assign all peaks. However, it is clear that this technique shows promise in the distinguishing and identification of tungsten species in environmental samples.

\subsection{Raman Spectroscopy}

From Figure 6a, three major peaks are identified at $929 \mathrm{~cm}^{-1}, 837 \mathrm{~cm}^{-1}$ and $333 \mathrm{~cm}^{-1}$ for sodium tungstate salt. These are in agreement with the peaks observed by Shijun et al. (934 $\mathrm{cm}^{-1}, 834 \mathrm{~cm}^{-1}$ and $325 \mathrm{~cm}^{-1}$ ). In addition, some minor peaks are observed at $892 \mathrm{~cm}^{-1}, 809$ $\mathrm{cm}^{-1}, 282 \mathrm{~cm}^{-1}$ and $168 \mathrm{~cm}^{-1}$. The peak identified at $441 \mathrm{~cm}^{-1}$ does not appear to be significant compared to the others. Figure $6 \mathrm{~b}$ shows peaks associated with the paratungstate species. Raman shifts associated with the $\mathrm{NH}_{4}{ }^{+}$occur outside the current scanning range. More peaks are observed with the paratungstate salt than with any of the other salts. Major peaks occur at $948 \mathrm{~cm}^{-1}, 872 \mathrm{~cm}^{-1}, 804 \mathrm{~cm}^{-1}, 350 \mathrm{~cm}^{-1}, 317 \mathrm{~cm}^{-1}, 206 \mathrm{~cm}^{-1}$, and $164 \mathrm{~cm}^{-1}$ with minor peaks at $649 \mathrm{~cm}^{-1}, 568 \mathrm{~cm}^{-1}, 491 \mathrm{~cm}^{-1}$, and $428 \mathrm{~cm}^{-1}$. The peak at $948 \mathrm{~cm}^{-1}$ may be related to a similar peak in the spectrum of sodium tungstate at $929 \mathrm{~cm}^{-1}$. It is possible that these peaks originate from similar vibrations and the difference in the shifts may be due to the larger molecular structure of the paratungstate and the effects of other vibrations from the molecule. It is also observed that the base of this peak is broader than the one in the sodium tungstate spectrum. The Raman spectrum of pure sodium metatungstate salt (Figure 6c) shows major peaks at $979 \mathrm{~cm}^{-1}, 965 \mathrm{~cm}^{-1}, 233 \mathrm{~cm}^{-1}, 195 \mathrm{~cm}^{-1}$, and $163 \mathrm{~cm}^{-1}$. The bases of these peaks are generally broader than the other salts. The region between $1000 \mathrm{~cm}^{-1}$ and $900 \mathrm{~cm}^{-1}$ reveals two peaks which may be related to the previously discussed peaks in the same regions of the sodium tungstate and ammonium paratungstate spectra. However, these peaks are less acute which may also be indicative of the influence of other molecular bonds and vibrations.

From the comparison of Figures $6 a$, b, and $c$, the active regions for each salt can be easily identified. The Raman spectra of these three species are quite distinct and could hold the key to possible qualitative analysis. 


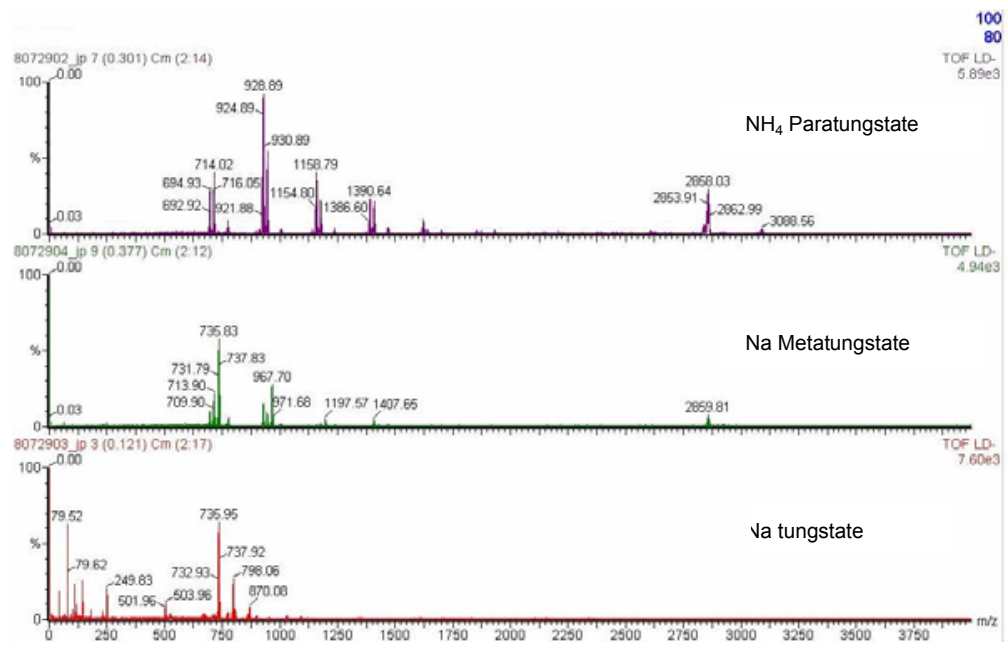

(a)

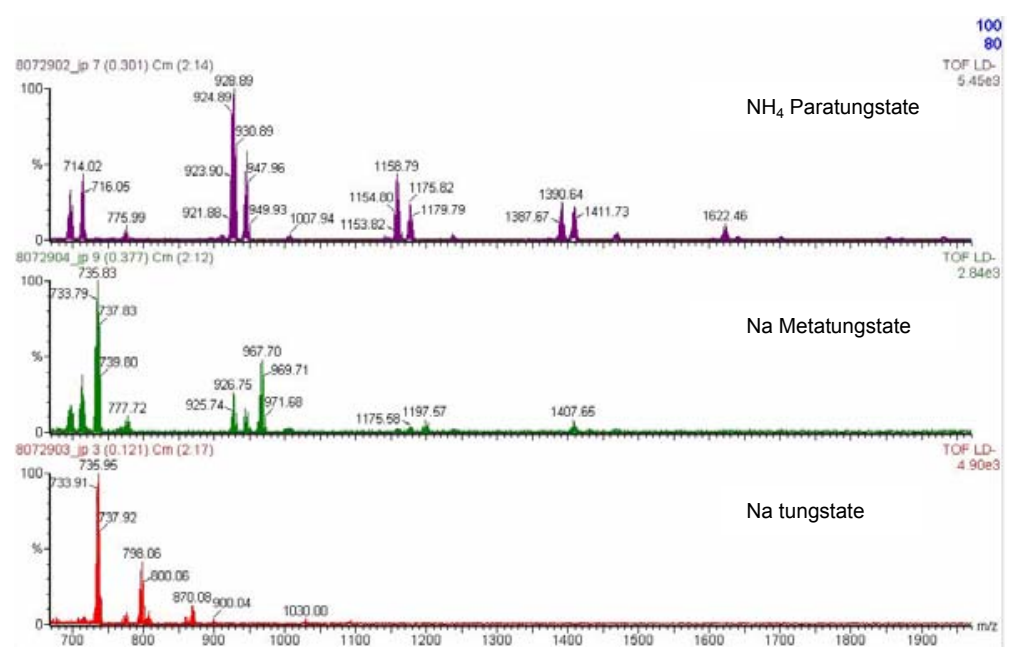

(b)

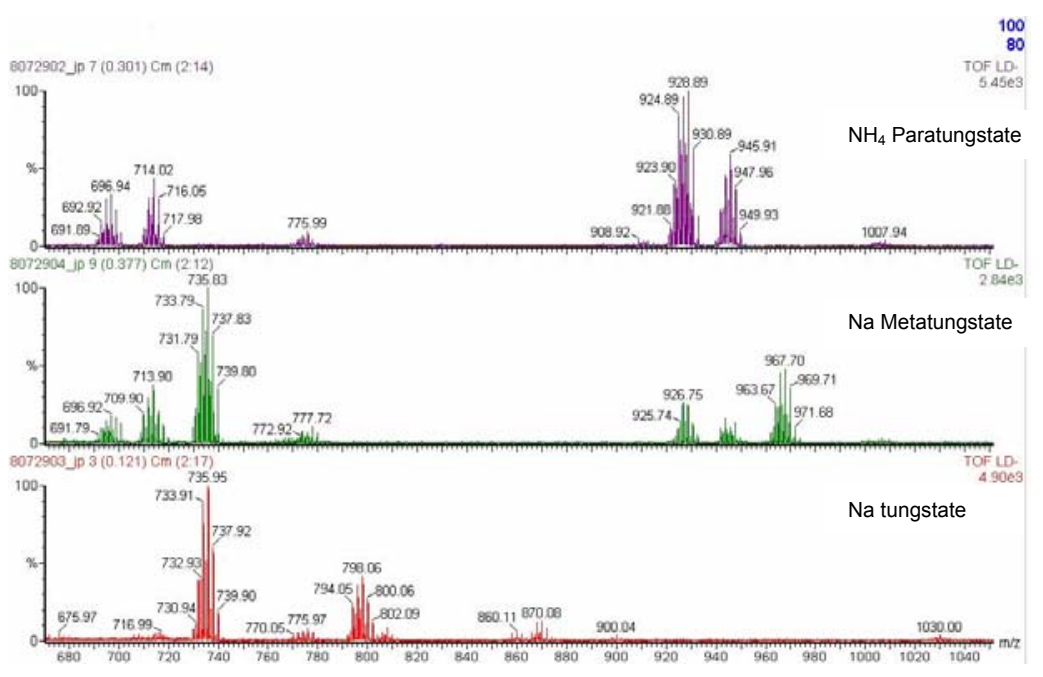

(c)

Figure 2. Comparison of the LDI-TOF spectra of sodium tungstate, sodium metatungstate, ammonium paratungstate at different zoom scales 


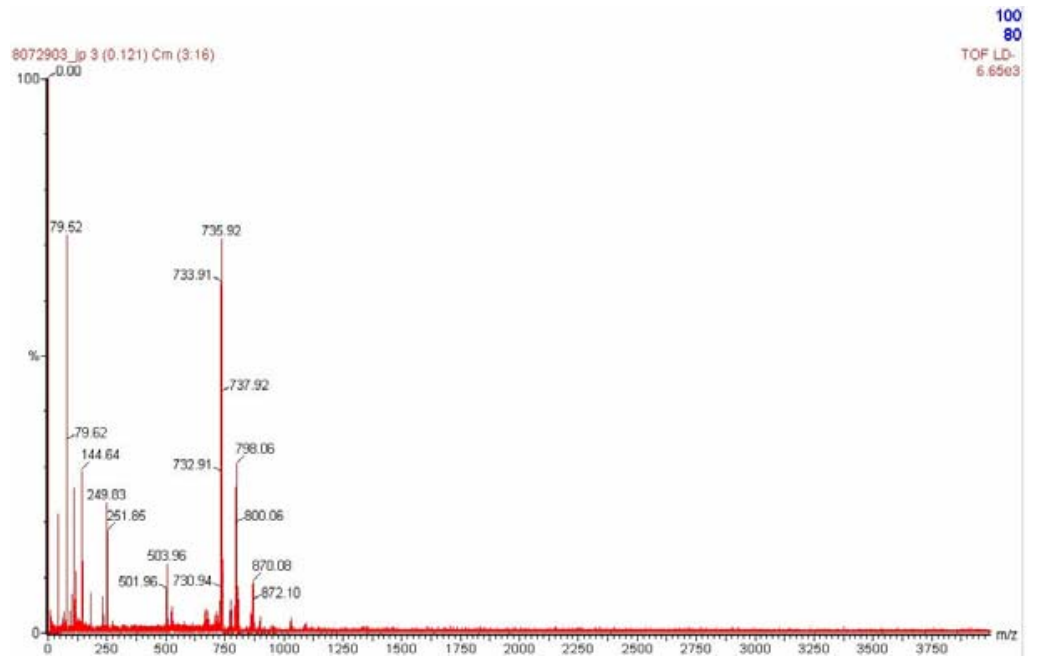

(a)

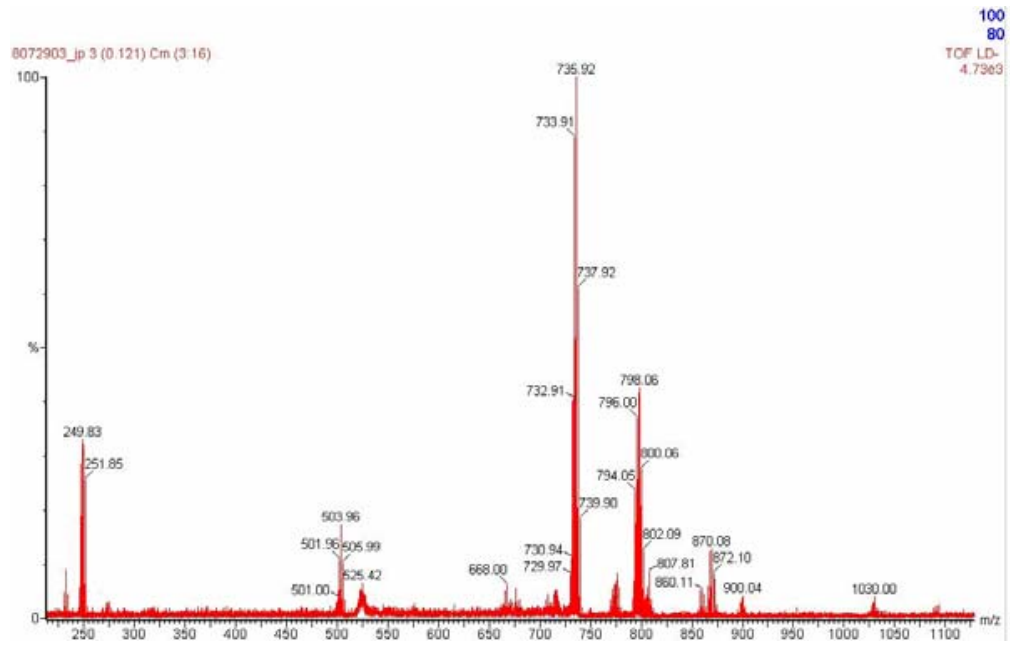

(b)

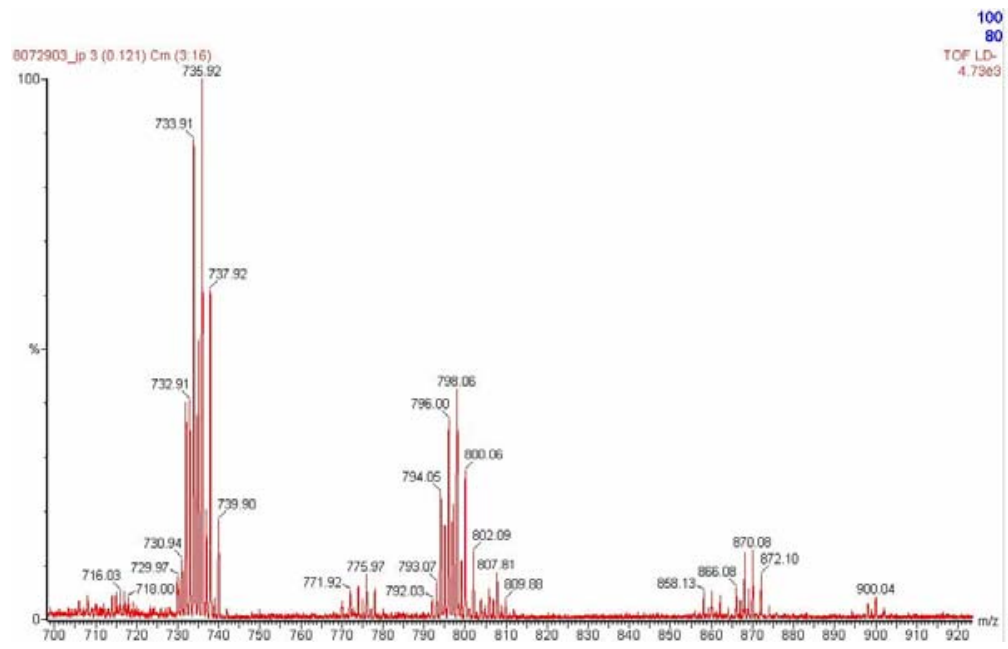

(c)

Figure 3. LDI-TOF spectra of sodium tungstate at different zoom scales 


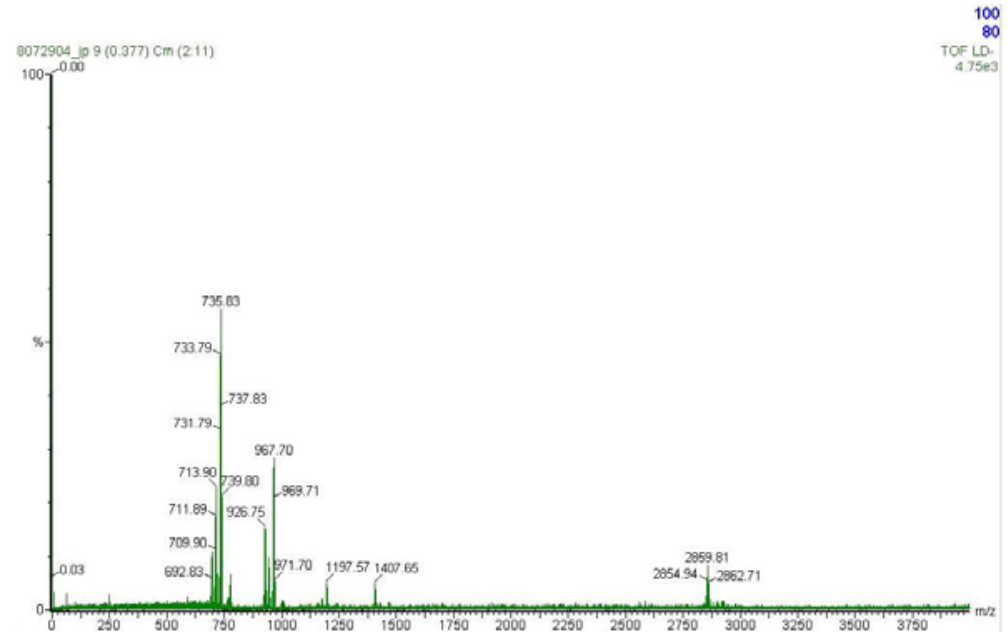

(a)

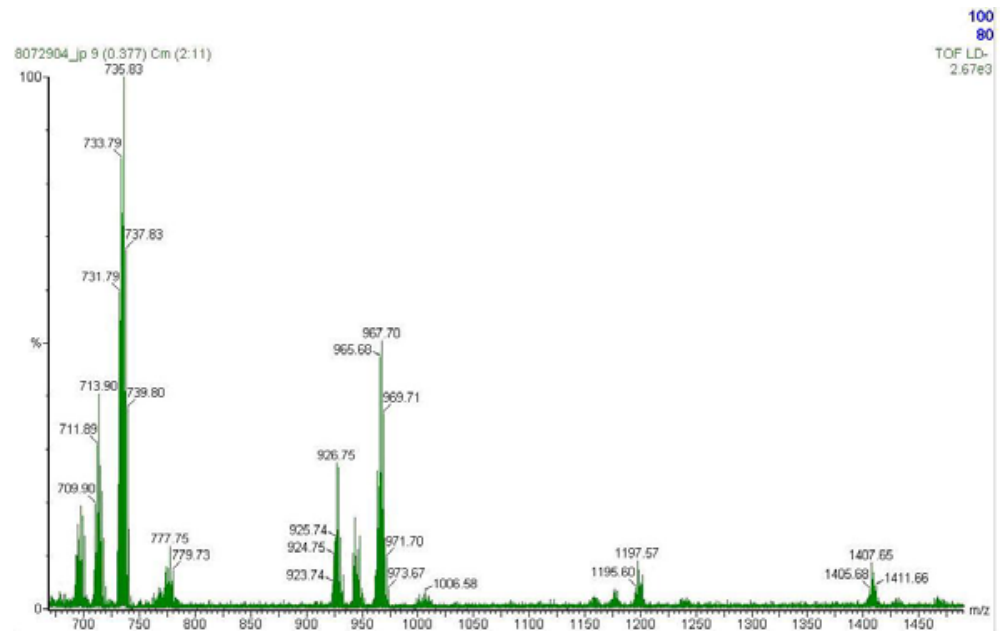

(b)

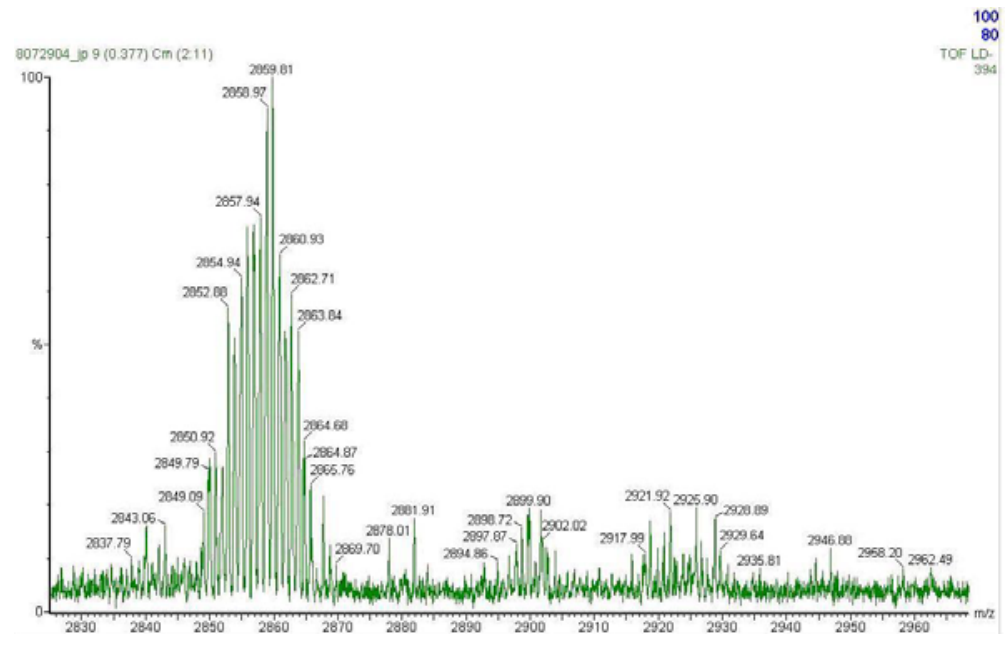

(c)

Figure 4. LDI-TOF spectra of sodium metatungstate. at different zoom scales 


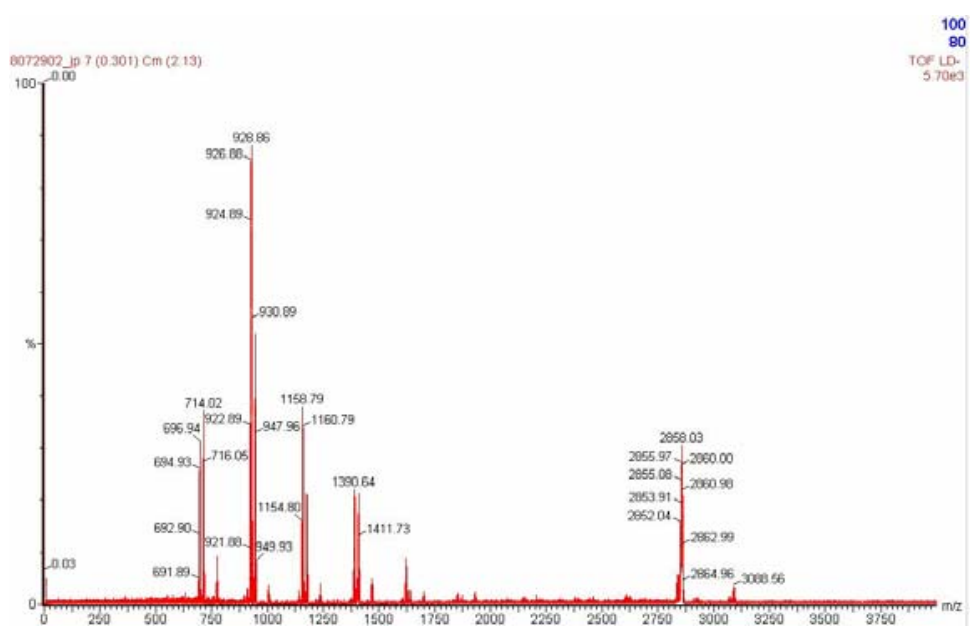

(a)

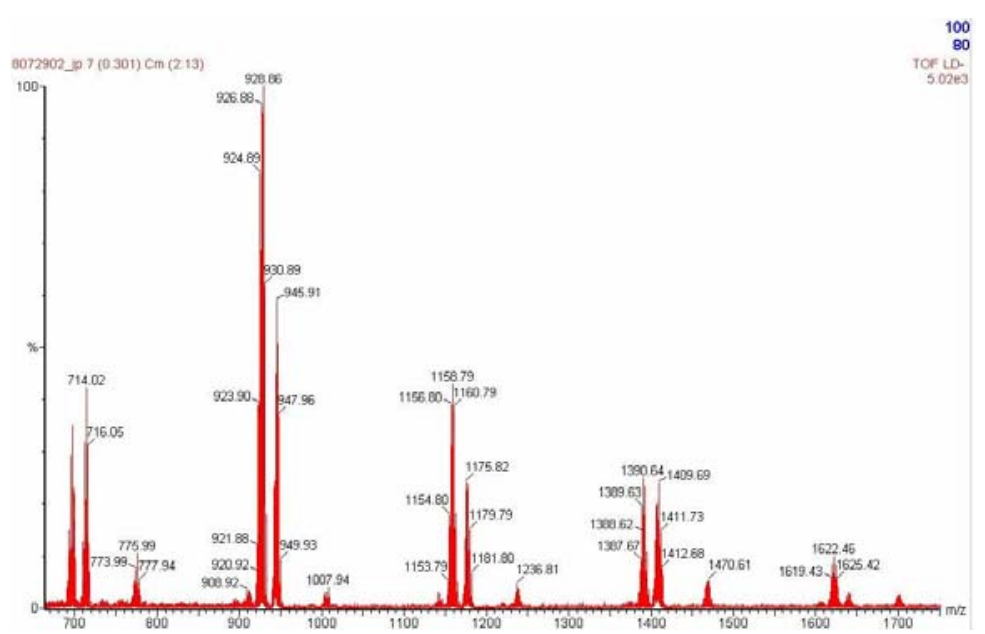

(b)

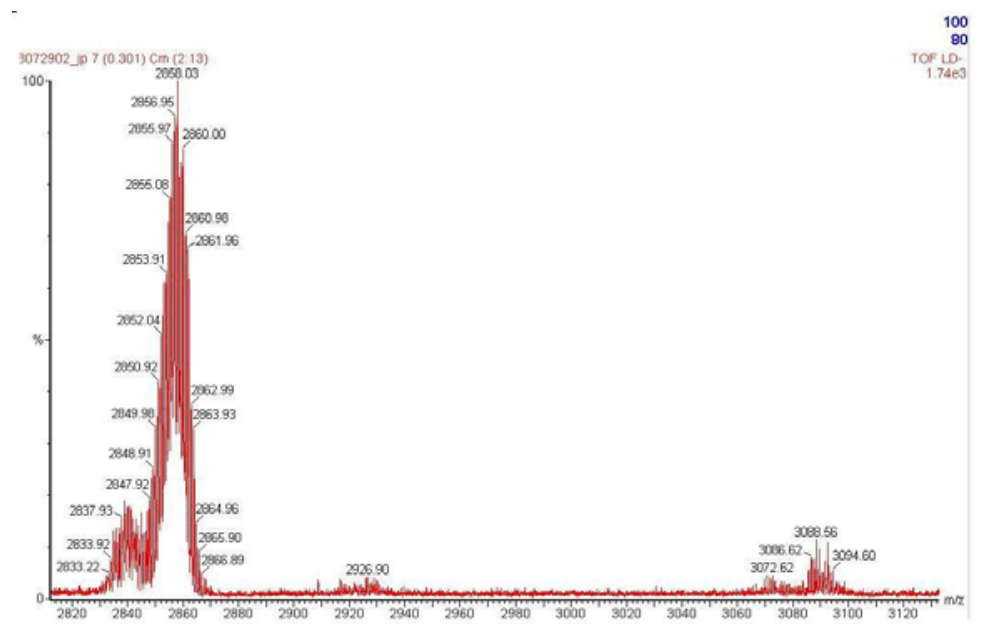

(c)

Figure 5. LDI-TOF spectra of ammonium paratungstate at different zoom scales 


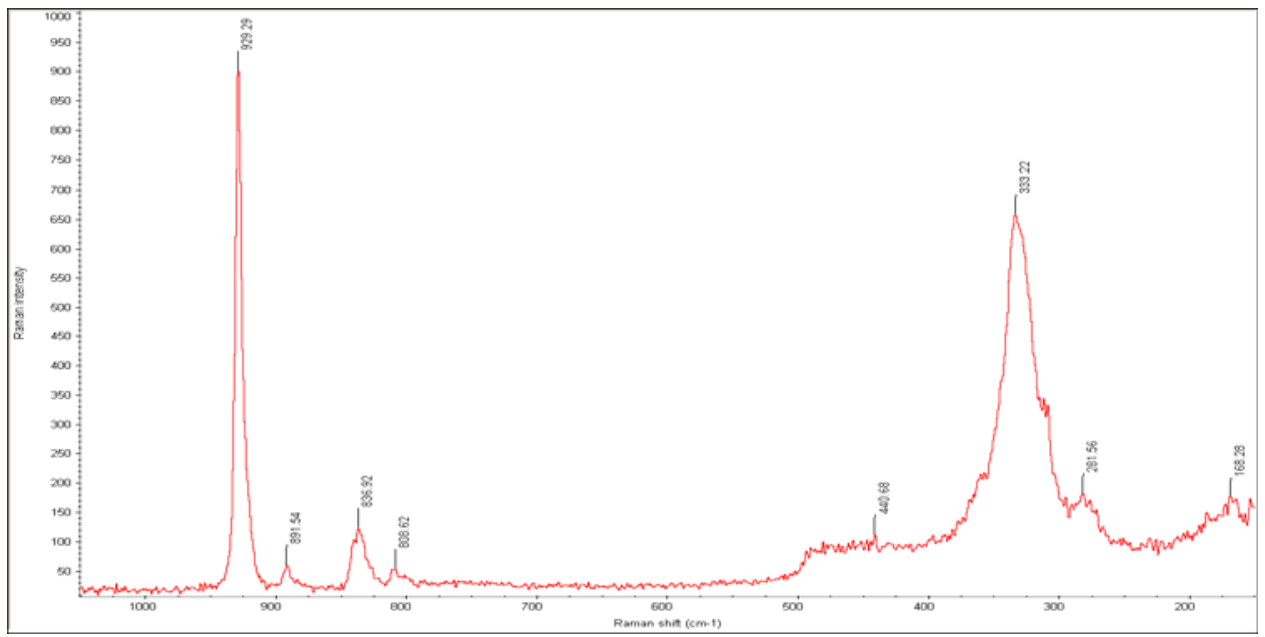

(a)

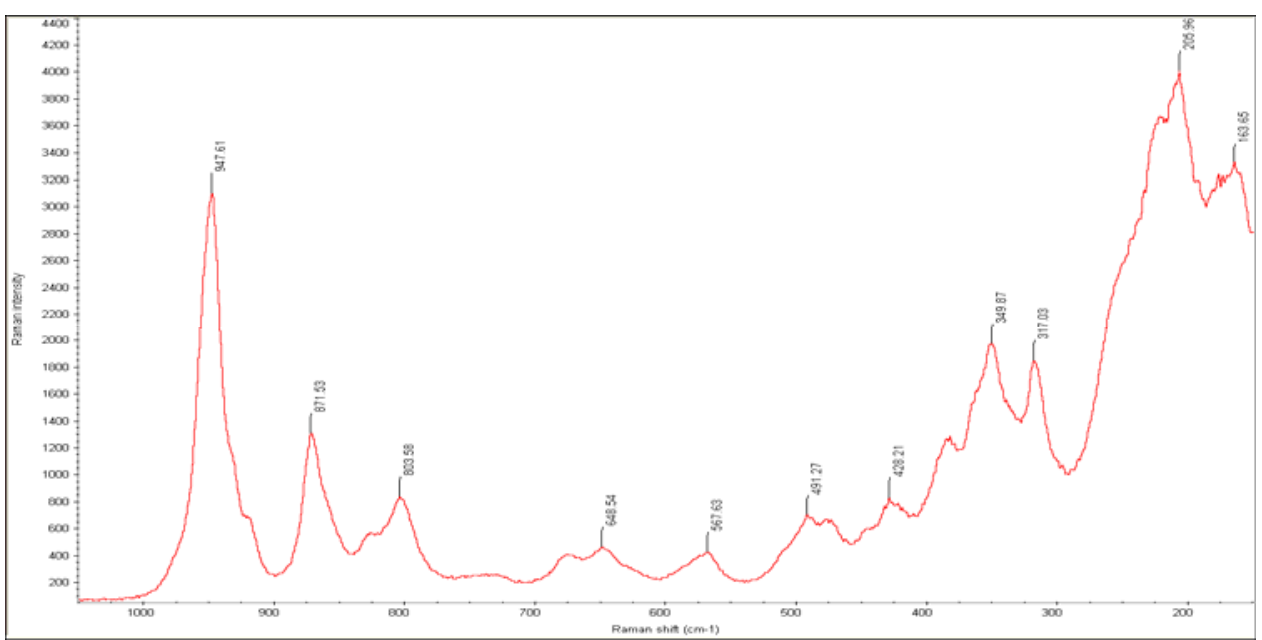

(b)

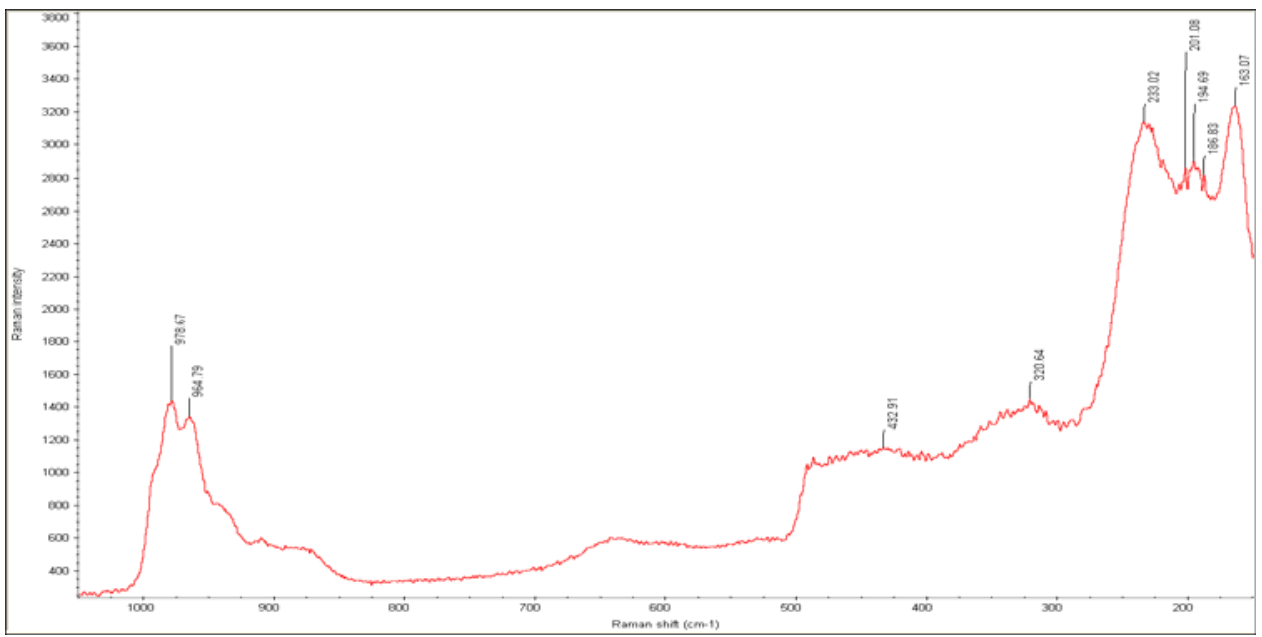

(c)

Figure 6. Raman Spectrum of: a) pure sodium tungstate, b) ammonium paratungstate, and c) sodium metatungstate 


\section{CONCLUSIONS}

Currently, there are not analytical techniques available to assess speciation of tungsten in environmental samples beyond the distribution between monomeric and polymeric species. The results presented here show that both LDI-TOF and Raman spectroscopy appear to be viable methods for qualitative and semi-quantitative analysis of tungsten speciation. However, more detailed analyses need to be performed to assign all MS peaks and to improve the resolution of Raman spectra.

\section{ACKNOWLEDGEMENT}

The authors would like to express their profound gratitude to the staff of the Center for Mass Spectrometry at Stevens Institute of Technology.

\section{REFERENCES}

Agency for Toxic Substances and Disease Registry (ATSDR) (2003) Draft Toxicological Profile for Tungsten, U.S. Department of Health and Human Services, Public Health Service Agency for Toxic Substances and Disease Registry, Atlanta, GA, U.S.A.

Bednar A.J., Mirecki J.E., Inouye L.S., Winfield L.E., Larson S.L. and Ringelberg D.B. (2007) The determination of tungsten, molybdenum, and phosphorous oxyanions by high performance liquid chromatography inductively coupled plasma mass spectrometry, Talanta, 72, 18281832.

Chojnacka J. (1971) Application of isomatrix electromigration to the investigation of the condensation of the $\mathrm{WO}_{4}{ }^{2-}$ ions" J. Inorg. Nucl. Chem., 33, 1345-1363

Cruywagen J.J. and Van Der Merwe I.F.J. (1987) Tungsten (VI) equilibria: a potentiometric and calorimetric investigation, Journal Chem. Soc. Dalton Transactions, 7, 1701-1705.

Cruywagen J.J. (2000) Protonation oligomerization and condensation reactions of vanadate (V), molybdate (VI), and tungstate (VI), Advances in Inorganic Chemistry, 49, 127-182.

Dermatas D., Braida W., Christodoulatos C., Strigul N., Panikov N., Los M. and Larson S. (2004) Solubility, sorption, and soil respiration effects of tungsten and tungsten alloys, Environ. Forensics, 5, 5-13.

Hastings J.J. and Howarth O.W. (1992) A ${ }^{183} \mathrm{~W},{ }^{1} \mathrm{H}$ and ${ }^{17} \mathrm{O}$ nuclear magnetic resonance study of aqueous isopolytungstates, Journal Chem. Soc. Dalton Transactions, 2, 209-215.

Jander G., Mojert D. and Aden T. (1929) Über amphotere Oxydhydrate, deren wäßrige Lösungen und kristallisierende Verbindungen. VIII. Mitteilung. Über Wolframate, Isopoly- und Heteropoly-Wolframsäuren, Z. Anorg. Allg. Chem., 180(1), 129-149.

Ng K.Y.S and Gulari E. (1984) Spectroscopic and scattering investigation of isopoly-molybdate and tungstate solutions, Polyhedron, 3, 1001-1011.

Ogundipe A. (2006) Environmental Release Mechanisms of Tungsten and Alloying Elements from Tungsten Heavy Alloys, PhD Dissertation, Department of Civil, Environmental and Ocean Engineering, Stevens Institute of Technology, Hoboken, NJ.

Sasaki Y. (1961) Equilibrium studies of polyanions, Acta Chemica Scandinavica, 15, 175-189.

Shijun L., Qiyuan C., Pingmin Z. and Songqin L. (1998) Raman spectral study on isopolytungstates in aqueous solution, Trans. Nonferrous Met. Soc. China, 8(4), 688-692.

Smith B.J. and Patrick V.A. (2000) Quantitative determination of sodium metatungstate speciation by ${ }^{183}$ W N.M.R. spectroscopy, Aust. J. Chem., 53, 965-970.

Strigul N., Koutsospyros A. and Christodoulatos C. (2009) Tungsten speciation and toxicity: acute toxicity of mono- and poly-tungstates to fish, Ecotoxicology and Environmental Safety, (accepted).

Tajima Y. (2003) The effects of tungstophosphate and tungstosilicate on various stress promoters transformed in Escherichia Coli, . Journal of Inorganic Biochemistry, 94, 155-160. 